\title{
Avaliação do Processo de Revestimento com Argamassa Projetada: Aspectos Econômicos e Ambientais
}

\author{
Cristina Toca Pérez \\ Dayana Bastos Costa \\ Jardel Pereira Gonçalves
}

\section{Introdução}

Entre os sistemas de revestimento disponíveis no mercado brasileiro, o sistema com uso de argamassa é o mais utilizado (PARAVISI, 2008). Esse tipo de revestimento pode ser constituído de mais de uma camada, sendo denominadas de emboço e reboco, ou pode possuir apenas uma camada, chamada de massa única (PARAVISI, 2008).

No intuito de melhorar o desempenho dos processos, o mercado da indústria da construção civil vem implantado inovações tecnológicas, como o sistema de revestimento por meio de argamassas projetadas (CRESCENCIO et al., 2000). No entanto, poucos são os estudos que têm avaliado os impactos dos sistemas de execução de revestimentos com argamassa projetada, principalmente do ponto de vista econômico e ambiental.

O objetivo principal do presente capítulo é apresentar os resultados de uma pesquisa que visa avaliar o processo de revestimento com argamassa projetada do ponto de vista de seus aspectos econômicos e ambientais, a partir de quatro estudos 
de caso realizados na região metropolitana de Salvador. Para tanto, foi definido um conjunto de indicadores que orientaram tal avaliação de desempenho e, finalmente é feita uma comparação entre os estudos.

\section{Sistema de Revestimento com Argamassa por Projeção}

O sistema de projeção mecânica trata-se da aplicação de argamassa por meio de equipamentos de projeção em uma superfície a ser protegida ou recuperada, com espessura média variável de 3 a $5 \mathrm{~cm}$. Duas classificações podem ser utilizadas para categorizar o sistema de revestimento com argamassa por projeção, quais sejam: (a) segundo a forma de projeção; e (b) segundo a mobilidade da argamassa no canteiro (PARAVISI, 2008).

O sistema de revestimento classificado segundo a forma de projeção pode ser divido em contínuo ou descontínuo. O processo contínuo é realizado por meio de bombas que aplicam a argamassa no substrato sem interrupções no processo, desde que haja uma alimentação constante. As bombas de projeção convencionais são exemplos de processo contínuo. O processo descontínuo é realizado por projetores a ar comprimido, nos quais a argamassa é colocada diretamente em um recipiente, havendo uma quebra do processo de aplicação (CRESCENCIO et al., 2000; PARAVISI, 2008). O projetor por spray a ar comprimido (canequinha) é um exemplo de processo descontínuo.

Quanto à classificação segundo a mobilidade da argamassa, tem-se a subdivisão em sistemas estacionários e móveis. No primeiro, há a utilização de silos que distribuem a argamassa por via seca ou por via úmida até o local de aplicação. No transporte por via seca, o silo é pressurizado e, acoplado a ele, existe um compressor responsável por bombear a mistura seca até o local de aplicação, onde será adicionada água. No transporte por via úmida, a mistura de água ocorre no misturador abaixo do silo, produzindo a argamassa. O sistema móvel utiliza argamassa ensacada e, junto com o equipamento de mistura (misturador e bomba), são transportados entre os pavimentos nos quais será realizada a projeção (CRESCENCIO et al., 2000; PARAVISI, 2008).

\section{Indicadores para Avaliação do Sistema de Revestimento com Argamassa por Projeção}

A presente seção apresenta um conjunto de indicadores econômicos e ambientais que podem ser usados para avaliar o processo de execução de revestimentos com argamassa ou outros processos construtivos. 


\subsection{Avaliação Econômica}

A seguir, serão discutidos os indicadores para avaliação econômica.

\subsection{1 Índices de Produtividade}

Para mensuração da produtividade, dois índices podem ser utilizados, quais sejam: Razão Unitária de Produção (RUP) e Porcentagem de Tempo Produtivo (PTP).

A RUP é representada pela razão entre entradas (homens-hora demandados) e saídas (quantidade de serviço executado), conforme proposto por Souza e Mekbekian (2006). Um dos indicadores possíveis de serem levantados é a RUP cumulativa, que, segundo Souza e Mekbekian (2006), deve ser calculada por meio da razão entre os somatórios dos homens-hora demandados e das quantidades de serviço produzidas diariamente, durante todo o período de estudo (Equação 1).

$$
\mathrm{RUP}_{\mathrm{c}}=\frac{\sum \mathrm{Hh}}{\sum \mathrm{QS}}
$$

Onde:

RUPC = Razão Unitária de Produção cumulativa $\left(\mathrm{Hh} / \mathrm{m}^{2}\right)$;

$\Sigma \mathrm{Hh}=$ Somatório dos homens-hora demandados ao final do período de estudo (Hh);

$\Sigma Q S=$ Somatório da quantidade de serviço realizada ao final do estudo $\left(\mathrm{m}^{2}\right)$.

O PTP representa a porcentagem de tempo total do processo destinado a atividades que agregam valor ao produto (SANTOS; FORMOSO; HINKS, 1996). No processo de revestimento de argamassa por projeção, tais atividades são realizadas pela equipe direta, ou seja, trabalhadores envolvidos diretamente com o processo. Esse indicador pode ser calculado por meio da técnica de Amostragem do Trabalho (OLIVEIRA et al., 1995), que será discutida no item 4. Esse indicador é calculado a partir da Equação 2, conforme a seguir.

$$
\mathrm{PTP}=\frac{\mathrm{OP} \times 100}{\mathrm{OT}}
$$

Onde:

PTP =Porcentagem de Tempos Produtivos em atividades que agregam valor (\%);

$\mathrm{OP}=$ Número de observações identificadas na realização de atividades produtivas pela equipe direta;

OT = Número total de observações realizadas durante as atividades da equipe direta. 


\subsection{2 Índice de Perdas por Variação de Espessura}

A variação percentual de espessura média em relação à especificada em projeto tem o objetivo de medir as perdas de argamassa devido à espessura do revestimento, as quais são causadas pela falta de esquadro e de prumo das estruturas e alvenarias (PALLIARI et al., 2001). Para o cálculo desse indicador são realizadas medições em 30\% das taliscas de todas as superfícies a serem revestidas e utiliza-se a Equação 3.

$$
\operatorname{Var}_{\text {espessura }}(\%)=\left[\left(\mathrm{e}_{\text {média }}-\mathrm{e}_{\text {projeto }}\right)-1\right] \times 100
$$

Onde:

Var. $_{\text {espessura }}^{=}$Variação da espessura média em relação à especificada em projeto (\%);

$\mathrm{e}_{\text {média }}=$ espessura média $(\mathrm{cm})$;

$\mathrm{e}_{\text {projeto }}=$ espessura de projeto $(\mathrm{cm})$.

O cálculo do Indicador de Perdas por Variação de Espessura (Pvar. esp. ) é realizado a partir da fórmula expressada na Equação 4, que, por sua vez, é uma adaptação da fórmula proposta por Costa (2005).

$$
\text { Pvar. }_{\text {esp. }}=\frac{\mathrm{CR}-\mathrm{CP}}{\mathrm{CP}}
$$

Onde:

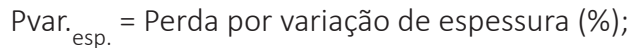

$C R=$ Consumo real necessário $\left(e_{\text {média }} \times\right.$ área produzida $)\left(\mathrm{m}^{3}\right)$;

$C P=$ Consumo previsto segundo a espessura de projeto $\left(e_{\text {projeto }} \times\right.$ área produzida $)\left(\mathrm{m}^{3}\right)$.

\subsection{3 Índicador de Perdas por Transporte}

As perdas por transporte podem ser definidas como todas as atividades de movimentação de materiais que geram custo e que não adicionam valor (PÉREZ; COSTA, GONÇALVES, 2016). Para o cálculo das perdas por transporte, foi adotado o indicador Percentual do Tempo Total destinado em Atividades de Transporte (PTAT), proposto por Pérez et al. (2016).

O PTAT objetiva identificar o tempo total destinado a atividades de transporte (necessárias, evitáveis e desnecessárias) em relação ao tempo total gasto pela equipe direta, a partir da Equação 5.

$$
\text { PTAT }=\frac{\text { OTAT }}{\text { OT }}
$$


Onde:

PTAT = Percentual do Tempo total destinado em Atividades de Transporte (\%);

OTAT = Número total de observações realizadas sobre a equipe direta executando Atividades de Transporte;

OT = Número total de observações realizadas durante as atividades da equipe direta.

\subsection{Avaliação Ambiental}

A seguir, serão discutidos os indicadores para avaliação ambiental.

\subsubsection{Nível de Pressão Sonora}

Para lida (2005), fisicamente, o ruído é uma mistura de vibrações, medidas em uma escala logarítmica, em uma unidade chamada decibel (dB). Acima do limiar da percepção dolorosa, pode produzir danos ao aparelho auditivo. O indicador Nível de Pressão Sonora (NPS) determina a intensidade do sonido que gera uma pressão sonora instantânea. Para a coleta deste indicador, duas medidas são realizadas. A primeira delas é feita junto aos equipamentos de mistura em funcionamento, e a outra, no local de projeção. A NR-15 - Atividades e operações insalubres (BRASIL, 2014) determina os seguintes valores para um determinado período de tempo:

- $\mathrm{L}_{\text {máximo }}=$ Valor máximo de NPS alcançado durante o estudo (dBA);

- $\mathrm{L}_{\text {mínimo }}=$ Valor mínimo $(\mathrm{dBA})$.

A classificação dos riscos de ruído estabelecidos pela NR-15 - Atividades e operações insalubres (BRASIL, 2014) é apresentada a seguir:

- Risco grave e iminente - NPS acima de $115 \mathrm{~dB}(\mathrm{~A})$;

- Risco grave - NPS acima de $100 \mathrm{~dB}(\mathrm{~A})$ e abaixo de $115 \mathrm{~dB}(\mathrm{~A})$;

- Risco médio - NPS entre 85 dB(A) e $100 \mathrm{~dB}(\mathrm{~A})$;

- Risco leve - NPS acima de $80 \mathrm{~dB}(\mathrm{~A})$ e abaixo de $85 \mathrm{~dB}(\mathrm{~A})$.

\subsubsection{Consumo de Água na Projeção}

Para estudar o consumo de água na produção de argamassas, fez-se necessário analisar o consumo de água por metro cúbico de argamassa produzido em central (SILVA; VIOLIN, 2013). Neste sentido, para o cálculo do consumo de água total no processo de revestimento com argamassa projetada é levado em conta o consumo de água para a elaboração do traço da mistura e o consumo de água para a limpeza dos equipamentos, conforme a Equação 6. 


$$
A=\frac{A_{\text {traço }}+A_{\text {equipamento }}}{V_{\text {real }}}
$$

Onde:

A = Água total consumida na projeção $\left(\mathrm{m}^{3} / \mathrm{m}^{3}\right)$;

$A_{\text {traço }}=$ Água consumida no traço $\left(\mathrm{m}^{3}\right)$;

$\mathrm{A}_{\text {equipamento }}=$ Água consumida na lavagem dos equipamentos $\left(\mathrm{m}^{3}\right)$;

$V_{\text {real }}=$ Volume de argamassa produzida $\left(\mathrm{m}^{3}\right)$.

É importante ressaltar que o valor de água gasto no traço da argamassa é variável com o fator A/Arg (água versus argamassa), podendo ser considerada a quantidade de água recomendada pelo fabricante da argamassa industrializada para a elaboração da mistura. Assim, o consumo de água no traço é o produto entre a constante dada pelo fabricante e a quantidade de argamassa utilizada, conforme Equação 7.

$$
A_{\text {traço }}=C_{\text {traço }} \times Q_{\text {argamassa }}
$$

(Equação 7)

Onde:

$\mathrm{A}_{\text {traço }}=$ Água consumida no traço $\left(\mathrm{m}^{3}\right)$;

$C_{\text {traço }}=8,5$ litros de água para cada $50 \mathrm{Kg}$ de argamassa $=\left(0,00017 \mathrm{~m}^{3} / \mathrm{kg}\right)$;

$\mathrm{Q}_{\text {argamassa }}=$ Quantidade de argamassa utilizada $(\mathrm{kg})$.

Para o cálculo da água consumida na lavagem dos equipamentos, pode-se levar em consideração as leituras dos hidrômetros antes e depois da projeção, descontado o consumo de água no traço, conforme a Equação 8.

$$
A_{\text {equipamento }}=\left[\left(L_{f}-L_{i}\right)\right]-A_{\text {traço }}
$$

Onde:

$\mathrm{A}_{\text {equipamento }}=$ Água consumida na lavagem dos equipamentos $\left(\mathrm{m}^{3}\right)$.

$\mathrm{L}_{\mathrm{f}}=$ Leitura final do hidrómetro $\left(\mathrm{m}^{3}\right)$;

$\mathrm{L}_{\mathrm{i}}=$ Leitura inicial $\left(\mathrm{m}^{3}\right)$;

$\mathrm{A}_{\text {traço }}=$ Água consumida no traço $\left(\mathrm{m}^{3}\right)$.

\subsubsection{Consumo de Energia Elétrica do Sistema de Projeção (E)}

O consumo de energia elétrica leva em consideração a potência dos equipamentos envolvidos no processo (argamassadeira e bomba de ar comprimido), bem como o tempo de funcionamento deles, conforme a Equação 9.

$$
E=\frac{P \times d}{V_{\text {real }}}
$$


Onde:

$E=$ Energia consumida pelos equipamentos $\left(\mathrm{Kwh} / \mathrm{m}^{3}\right)$.

$\mathrm{P}=$ Potência do equipamento $(\mathrm{W})$;

$d$ = Duração do equipamento em funcionamento (h);

$\mathrm{V}_{\text {real }}=$ Volume de argamassa produzida $\left(\mathrm{m}^{3}\right)$.

\section{Método de Pesquisa}

Este trabalho foi desenvolvido por meio de quatro estudos de caso na Região Metropolitana de Salvador, na Bahia, no período de setembro de 2012 até setembro de 2014. Cada estudo de caso foi desenvolvido em quatro etapas, conforme apresentado no Quadro 1.

Quadro 1 - Períodos e Etapas dos Estudos de Caso.

\begin{tabular}{|l|l|l|l|l|}
\hline Etapas da pesquisa & Estudo A & Estudo B & Estudo C & Estudo D \\
\hline $\begin{array}{l}\text { Seminário de } \\
\text { apresentação }\end{array}$ & $15 / 09 / 2012$ & $11 / 03 / 2013$ & $04 / 06 / 2013$ & $30 / 04 / 2014$ \\
\hline $\begin{array}{l}\text { Identificação dos } \\
\text { fluxos físicos }\end{array}$ & $16 / 09 / 12$ & $12 / 03 / 2013$ & $\begin{array}{l}06 / 05 a \\
12 / 05 / 13\end{array}$ & $\begin{array}{l}06 / 05 a \\
12 / 05 / 14\end{array}$ \\
\hline $\begin{array}{l}\text { Coleta dos } \\
\text { indicadores }\end{array}$ & $\begin{array}{l}17 / 09 \text { a } \\
06 / 12 / 12\end{array}$ & $\begin{array}{l}13 / 05 a \\
12 / 04 / 13\end{array}$ & $\begin{array}{l}13 / 05 a \\
17 / 07 / 13\end{array}$ & $\begin{array}{l}13 / 05 \\
17 / 07 / 14\end{array}$ \\
\hline Avaliação do estudo & $\begin{array}{l}07 / 12 / 12 \text { a } \\
01 / 02 / 13\end{array}$ & $\begin{array}{l}13 / 04 a \\
01 / 05 / 13\end{array}$ & $\begin{array}{l}18 / 07 \text { a } \\
30 / 07 / 13\end{array}$ & $\begin{array}{l}18 / 09 a \\
05 / 09 / 14\end{array}$ \\
\hline
\end{tabular}

A primeira etapa consistiu na realização de um seminário no canteiro de obra de cada estudo, visando explicar aos engenheiros e estagiários quais seriam as atividades realizadas durante as visitas a campo, assim como a designação das atribuições tanto da equipe de pesquisa como da equipe de obra. A segunda etapa correspondeu à identificação dos fluxos físicos a partir do mapeamento de todas as atividades de fluxo de materiais e mão de obra. A terceira etapa consistiu na coleta de indicadores, conforme Quadro 2. É importante mencionar que a coleta de indicadores em cada obra foi diferenciada, devido aos objetivos estabelecidos para cada estudo. Os estudos A, B e C tiveram como foco uma análise mais geral sobre o processo de revestimento de argamassa por projeção, abordando aspectos econômicos e ambientais. O estudo D focou na avaliação desse sistema construtivo, do ponto de vista das perdas por transporte, como parte da dissertação de mestrado de Pérez (2015). A última etapa envolveu a avaliação final do estudo e a comparação entre os casos quando possível. 
Quadro 2 - Indicadores coletados em cada estudo.

\begin{tabular}{|l|l|l|l|l|l|l|l|l|}
\hline & \multicolumn{3}{|l|}{ Aspectos Econômicos } & \multicolumn{3}{l|}{ Aspectos Ambientais } \\
\cline { 2 - 9 } & $\begin{array}{l}\text { Índices de } \\
\text { Produtividade }\end{array}$ & $\begin{array}{l}\text { Índice de Perdas } \\
\text { por Variação } \\
\text { Espessura }\end{array}$ & $\begin{array}{l}\text { Índices de } \\
\text { Perdas por } \\
\text { transporte }\end{array}$ & $\begin{array}{l}\text { Nível de } \\
\text { Pressão } \\
\text { Sonora }\end{array}$ & $\begin{array}{l}\text { Consumo } \\
\text { de água }\end{array}$ & $\begin{array}{l}\text { Consumo } \\
\text { de energia }\end{array}$ \\
\cline { 2 - 9 } & RUP & PTP & Pvar. ${ }_{\text {esp. }}$ & PTAT & NPS & A & E \\
\hline Estudo A & $X$ & - & $X$ & - & $X$ & $X$ & $X$ \\
\hline Estudo B & $X$ & - & $X$ & - & $X$ & - & - \\
\hline Estudo C & $X$ & - & - & - & $X$ & - & - \\
\hline Estudo D & - & $X$ & - & $X$ & - & - & - \\
\hline
\end{tabular}

O Quadro 3 resume as principais características dos casos e da coleta geral de dados, destacando-se os períodos de coleta, a descrição dos empreendimentos e a descrição dos processos de revestimento com argamassa estudados. Neste trabalho, foi considerado revestimento à base de argamassa, tanto o sistema emboço/reboco como o de massa única.

Quadro 3 - Características dos Estudos de Caso.

\begin{tabular}{|l|l|l|l|}
\hline & $\begin{array}{l}\text { Caraterização da } \\
\text { coleta }\end{array}$ & $\begin{array}{l}\text { Descrição do } \\
\text { Empreendimento }\end{array}$ & $\begin{array}{l}\text { Descrição do Processo de } \\
\text { revestimento com argamassa }\end{array}$ \\
\hline Estudo A & $\begin{array}{l}10 \text { semanas } \\
32 \text { visitas de 2-3h }\end{array}$ & $\begin{array}{l}\text { Residencial alto padrão } \\
1 \text { torre de } 20 \text { andares }\end{array}$ & $\begin{array}{l}\text { Revestimento Interno } \\
\text { Projeção estacionária por via } \\
\text { úmida }\end{array}$ \\
\hline Estudo B & $\begin{array}{l}5 \text { semanas } \\
17 \text { visitas de 3-4h }\end{array}$ & $\begin{array}{l}\text { Empresarial } \\
\text { 2 torres de 23 e 15 andares }\end{array}$ & $\begin{array}{l}\text { Revestimento Externo sem } \\
\text { vãos } \\
\text { Projeção estacionária por via } \\
\text { úmida }\end{array}$ \\
\hline Estudo C & $\begin{array}{l}6 \text { semanas } \\
25 \text { visitas de 3-4h }\end{array}$ & $\begin{array}{l}\text { Residencial alto padrão } \\
\text { torres de 28 andares }\end{array}$ & $\begin{array}{l}\text { Revestimento Externo com } \\
\text { vãos } \\
\text { Projeção móvel }\end{array}$ \\
\hline Estudo D & $\begin{array}{l}13 \text { semanas } \\
32 \text { visitas de 4-6h }\end{array}$ & $\begin{array}{l}\text { Residencial alto padrão } \\
8 \text { torres de 16 andares }\end{array}$ & $\begin{array}{l}\text { Revestimento Interno } \\
\text { Projeção móvel }\end{array}$ \\
\hline
\end{tabular}

\subsection{Coleta de Dados}

Para a coleta e o registro das informações, foram utilizadas ferramentas e técnicas, envolvendo tanto a obtenção de dados qualitativos como quantitativos. Além 
disso, foram utilizados como fontes de evidências a análise de documentos, observação direta, anotações de campo, entrevistas e percepções das pessoas envolvidas e documentação fotográfica.

A seguir, são apresentadas as principais ferramentas, técnicas e instrumento utilizados para a coleta dos indicadores.

\subsubsection{Planilha de Controle da Produtividade}

Essa ferramenta foi utilizada para monitorar a produtividade dos operários, por meio de medições de quantidades produzidas e homem-horas gastas em ciclos de produção bem definidos. Os dados dessa ferramenta permitiram calcular a Razão Unitária de Produção (RUPc).

\subsubsection{Amostragem do Trabalho}

Essa técnica permite determinar como o operário utiliza seu tempo, o qual é dividido em tempos produtivos, auxiliares (transporte necessários, transportes auxiliares e outras atividades auxiliares) e improdutivos (transporte desnecessários e outras atividades improdutivas) (PÉREZ et al. 2016). A partir do uso dessa técnica, foi possível o cálculo dos indicadores Porcentagem de Tempo Produtivo (PTP) e Percentual do Tempo total destinado em Atividades de Transporte (PTAT).

\subsubsection{Planilha para o Controle de Argamassa}

Foi utilizado o método proposto por Costa (2005) para o controle da argamassa produzida. Tal método permitiu o controle diário das quantidades de argamassa que eram utilizadas no revestimento. Essas medidas eram obtidas com o apoio dos trabalhadores da central de argamassa. A partir do uso dessa ferramenta, foi possível o cálculo da Quantidade de argamassa utilizada (Qargamassa).

\subsubsection{Planilha para o Controle de Água}

Foi desenvolvida uma planilha para controlar a água incorporada na mistura e na limpeza dos equipamentos. Nessa planilha, eram anotadas as leituras dos hidrômetros antes e depois da projeção. A partir do uso dessa ferramenta junto com a Quantidade de argamassa utilizada ( $\mathrm{kg}$ ), foi possível calcular o Indicador Consumo de água na projeção (A). 


\subsubsection{Planilha para o Controle de Energia}

Foi criada uma fol ha de cálculo para controlar a energia gasta pelos equipamentos. Nessa planilha, era anotado o tempo total que os equipamentos permaneciam em funcionamento. A partir do uso dessa ferramenta junto com a Qargamassa, foi possível calcular o Indicador Consumo de Energia (E).

\subsubsection{Decibelímetro}

O Medidor de Nível de Pressão Sonora (MNPS), também chamado de decibelímetro, é um instrumento utilizado para realizar a medição dos NPS, e, consequentemente, intensidade de sons, já que o NPS é uma grandeza que representa razoavelmente bem a sensação auditiva de volume sonoro, quando ponderada. Esse equipamento é normalmente calibrado para ler o nível de som em decibéis (uma unidade logarítmica) (RODRIGUES et al., 2009). Dessa forma, tal equipamento permitiu, nesta pesquisa, coletar o Indicador Nível de Pressão Sonora (NPS).

O Quadro 4 apresenta um resumo dos instrumentos, técnicas e ferramentas utilizadas para a coleta dos indicadores utilizados no presente trabalho.

Quadro 4 - Instrumentos, Técnicas e Ferramentas utilizadas para a coleta dos indicadores.

\begin{tabular}{|l|l|}
\hline Indicador & Instrumentos, técnicas e ferramentas utilizadas \\
\hline Índices de produtividade & $\begin{array}{l}\text { Planilha para o controle da produtividade } \\
\text { Amostragem do trabalho }\end{array}$ \\
\hline Índice de perdas por variação de espessura & Planilha para o controle das espessuras \\
\hline Índice de perdas por transporte & Amostragem do trabalho \\
\hline Nível de pressão sonora & Decibelímetro \\
\hline Consumo de água & $\begin{array}{l}\text { Planilha para o controle de água } \\
\text { Planilha para o controle de argamassa }\end{array}$ \\
\hline Consumo de energia & $\begin{array}{l}\text { Planilha para o controle de energia } \\
\text { Planilha para o controle de argamassa }\end{array}$ \\
\hline
\end{tabular}

\section{Avaliação do Processo de Revestimento de Argamassa}

A seguir, são apresentados os resultados da análise econômica e ambiental do processo de revestimento com argamassa projetada para os estudos realizados nesta pesquisa. 


\subsection{Avaliação Econômica}

\subsubsection{Indicadores de Produtividade (RUPc e PTP)}

Os resultados do indicador de produtividade Razão Unitária de Produção Cumulativa (RUPc) nos Estudos A, B e C devem considerar as variáveis existentes em cada processo, as quais levaram aos resultados registrados, tais como configuração da equipe, tipo de sistema utilizado, tipo de transporte utilizado para a movimentação dos funcionários, dificuldades construtivas, entre outros, conforme apresentado no Quadro 5. Denominou-se, neste trabalho, equipe de produção de argamassa os funcionários encarregados das funções de dosagem e projeção da argamassa. Foram considerados pedreiros aqueles que realizavam apenas as funções de acabamento, como sarrafamento e desempeno.

Quadro 5 - Informações para o cálculo do Indicador RUPc nos Estudos A, B e C.

\begin{tabular}{|l|l|l|l|}
\hline & Estudo A & Estudo B & Estudo C \\
\hline Tipo de revestimento & Interno & $\begin{array}{l}\text { Externo sem } \\
\text { vãos }\end{array}$ & $\begin{array}{l}\text { Externo com } \\
\text { vãos }\end{array}$ \\
\hline Tipo de projeção & $\begin{array}{l}\text { Projeção } \\
\text { estacionária por } \\
\text { via úmida }\end{array}$ & $\begin{array}{l}\text { Projeção } \\
\text { estacionária por } \\
\text { via úmida }\end{array}$ & Projeção móvel \\
\hline $\begin{array}{l}\text { Equipamento de transporte para a } \\
\text { movimentação dos funcionarios }\end{array}$ & - & $\begin{array}{l}\text { Plataformas } \\
\text { aéreas }\end{array}$ & $\begin{array}{l}\text { Balancim } \\
\text { suspenso } \\
\text { mecanizado }\end{array}$ \\
\hline $\begin{array}{l}\text { Relação pedreiros: serventes: equipe } \\
\text { de produção de argamassa }\end{array}$ & $12: 3: 3$ & $8: 3: 3$ & $4: 2: 3$ \\
\hline RUPc pedreiro $\left(H \mathrm{~h} / \mathrm{m}^{2}\right)$ & 0,45 & 1,26 & 0,76 \\
\hline RUPc servente $\left(\mathrm{Hh}^{2} \mathrm{~m}^{2}\right)$ & 0,11 & 0,50 & 0,43 \\
\hline $\begin{array}{l}\text { RUPc equipe de produção de } \\
\left.\text { argamassa (Hh/m }{ }^{2}\right)\end{array}$ & 0,67 & 0,33 & 0,46 \\
\hline
\end{tabular}

Como pode ser observado no Quadro 5, os valores encontrados apresentaram uma variação entre 0,11 e 1,26 Hh/m². Comparando-se as RUPc, observa-se que o Estudo B apresentou o menor RUPc para a equipe de produção de argamassa $\left(0,33 \mathrm{Hh} / \mathrm{m}^{2}\right)$ entre os três estudos realizados. Porém, esse mesmo estudo apresentou o maior RUPc dos pedreiros $\left(1,26 \mathrm{Hh} / \mathrm{m}^{2}\right)$. Essa defasagem entre as equipes de produção e pedreiros pode ser explicada devido à reduzida frente de trabalho encontrada no canteiro, fato que propiciava à equipe de produção projetar uma grande área em apenas 2 horas de trabalho, ficando ociosa o restante do tempo (Figura 1). 
Entre os fatores que contribuíram para a maior produtividade dos pedreiros no Estudo $\mathrm{A}\left(0,45 \mathrm{Hh} / \mathrm{m}^{2}\right)$, dentre os três estudos, destaca-se a facilidade de movimentação dos trabalhadores, por se tratar do revestimento interno, assim como o tamanho da equipe, formada por 12 pedreiros (Figura 2), que conseguiu acompanhar a grande capacidade do equipamento de projeção.

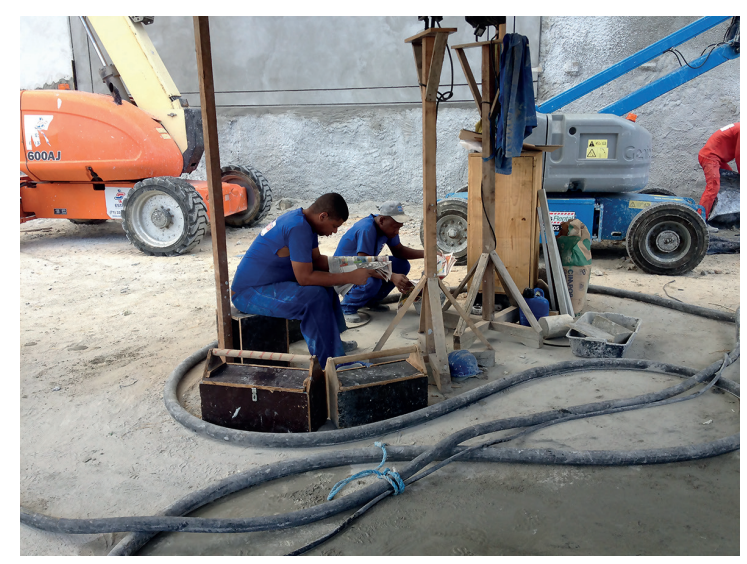

Figura 1 - Equipe de produção de argamassa do Estudo B ociosa. Fonte: Autores.

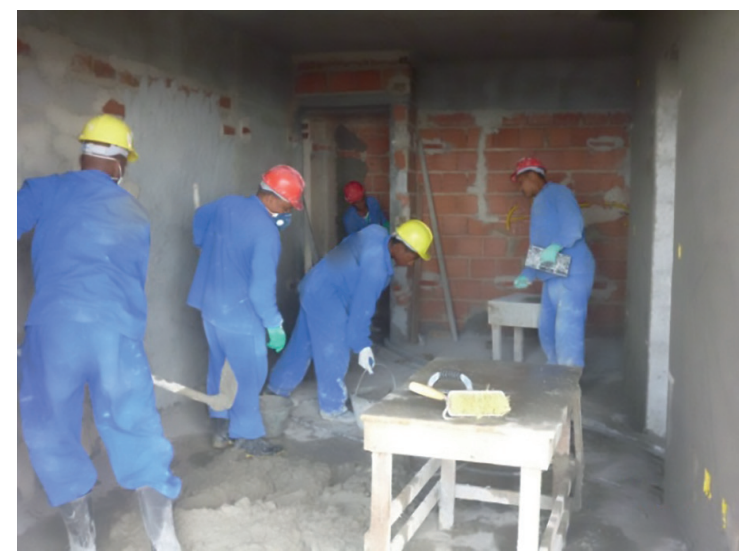

Figura 2 - Cinco funcionários trabalhando num único ambiente no Estudo A. Fonte: Autores.

Os dados da amostragem de trabalho para o cálculo do indicador PTP coletado no Estudo D foram comparados aos dados do estudo de Paravisi (2008), por ter sido o único estudo a calcular este indicador (Figura 3). 


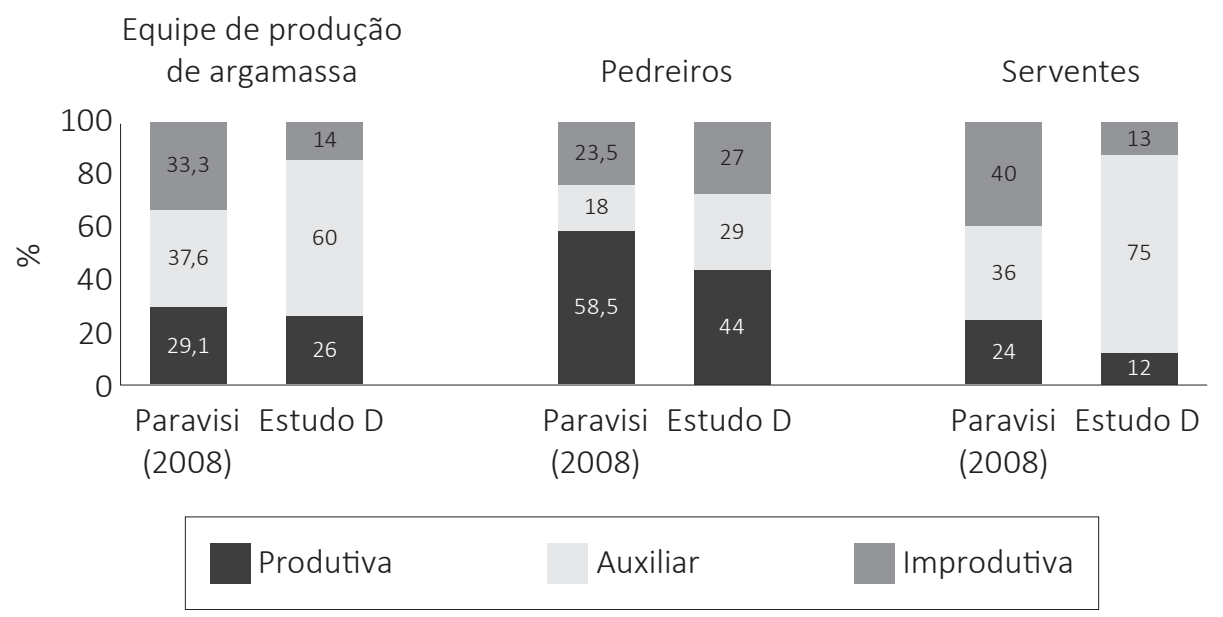

Figura 3 - Comparativo amostragem do trabalho no Estudo D com o Estudo de Paravisi (2008).

Observa-se, pela amostragem do trabalho, que a Porcentagem de Tempo Produtivo (PTP) da equipe de produção de argamassa foi de $26 \%$. Ao se separar os indicadores por função, no entanto, constata-se, no estudo $D$, que a produtividade da equipe de pedreiros foi de $44 \%$ e da equipe de serventes $12 \%$. Percebeu-se, no Estudo D, que as atividades de sarrafamento realizadas pelos pedreiros não acompanhavam o ritmo da projeção, embora os pedreiros dessa atividade apresentassem grandes tempos produtivos.

\subsubsection{Perdas por Variação de Espessura}

Nos Estudos A e B, foi calculado o Índice de Perdas por Variação de Espessura (Pvar. esp.), conforme apresentado no Quadro 6.

Quadro 6 - Indicadores utilizados para o cálculo da Pvar.esp.

\begin{tabular}{|l|l|l|l|l|l|l|}
\hline & $\begin{array}{l}\mathrm{e}_{\text {projeto }} \\
(\mathrm{cm})\end{array}$ & $\begin{array}{l}\mathrm{e}_{\text {média }} \\
(\mathrm{cm})\end{array}$ & $\begin{array}{l}\text { No de } \\
\text { amostras }\end{array}$ & $\begin{array}{l}\text { Área produzida } \\
\left(\mathrm{m}^{2}\right)\end{array}$ & $\begin{array}{l}\mathrm{CP} \\
\left(\mathrm{m}^{3}\right)\end{array}$ & $\mathrm{CR}\left(\mathrm{m}^{3}\right)$ \\
\hline Estudo A & 2,5 & 2,7 & 2131 & $16.653,16$ & 416,33 & 449,64 \\
\hline Estudo B & 2,0 & 3,0 & 50 & 1099,90 & 32,99 & 49,49 \\
\hline
\end{tabular}

A partir do Quadro 6, pode-se observar que em ambos estudos a espessura média executada ultrapassou o valor do projeto, de modo que a Variação da espessura

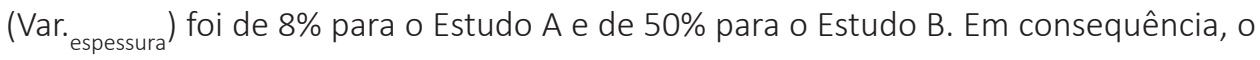


Pvar. esp. foi de 8\% para o Estudo A e de 50\% para o Estudo B. O alto valor encontrado de Pvar. esp. no Estudo B pode ser devido, entre outros fatores, à menor representatividade das amostras coletadas, em virtude da dificuldade de coletar tais amostras por se tratar de revestimento de fachada. Outro fator influenciador pode ter sido a falta de esquadro e de prumo das estruturas e alvenarias, propiciando a necessidade de incorporação de mais argamassa, conforme pode ser observado na Figura 4. No Estudo $B$, foi inclusive necessária a instalação de tela de PVC para garantir a aderência entre camadas, conforme indicado pela NBR 13749 (ABNT, 1996), nas áreas com espessuras maiores a 4,0cm (Figura 5).

Comparando os resultados encontrados com trabalhos prévios, destaca-se que Paliari et al. (1999) encontrou perda por sobre-espessura dos revestimentos com argamassa de $82 \%$ e Costa (2005), de $21 \%$.

Analisando a distribuição das espessuras (Figura 6) dentro dos intervalos de valores mínimos e máximos nos Estudos A e B, observa-se que 61,0\% das espessuras do Estudo A e 30\% das espessuras do Estudo B estão no intervalo de 2,0 a 3,0 cm, medidas recomendadas pela norma NBR 13749 (ABNT, 1996). No entanto, há espessuras com valores muito acima de 4,00 cm, observadas em $9 \%$ dos valores para o Estudo A e 22,5\% para o Estudo B. Estas espessuras requerem especial atenção por contribuir com as perdas e por deixar o revestimento vulnerável a falhas futuras, principalmente com um maior risco de descolamento, situação que foi identificada em várias ocasiões no Estudo B (Figura 7).

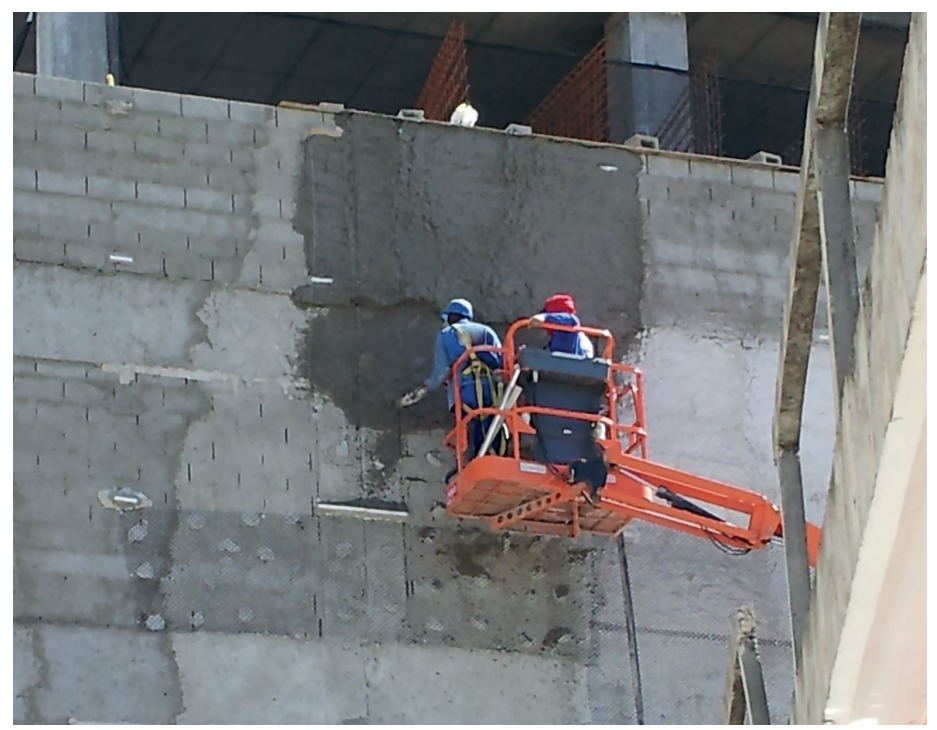

Figura 4 - Falta de esquadro entre a alvenaria e a estrutura. Fonte: Autores. 


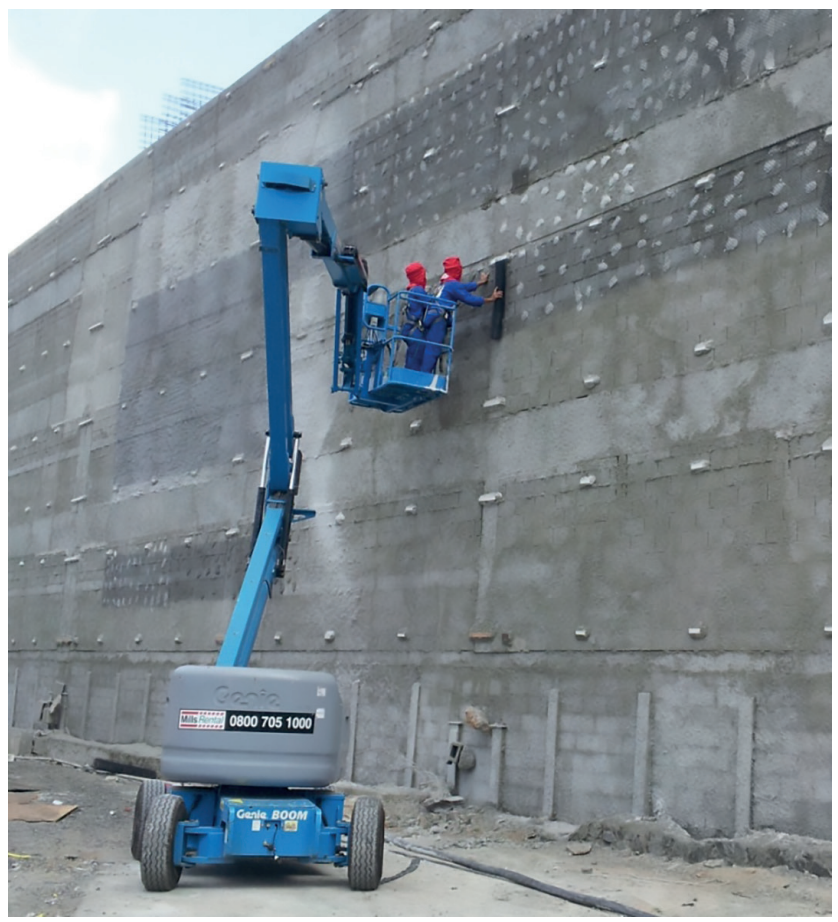

Figura 5 - Aplicação de tela de PVC. Fonte: Autores.

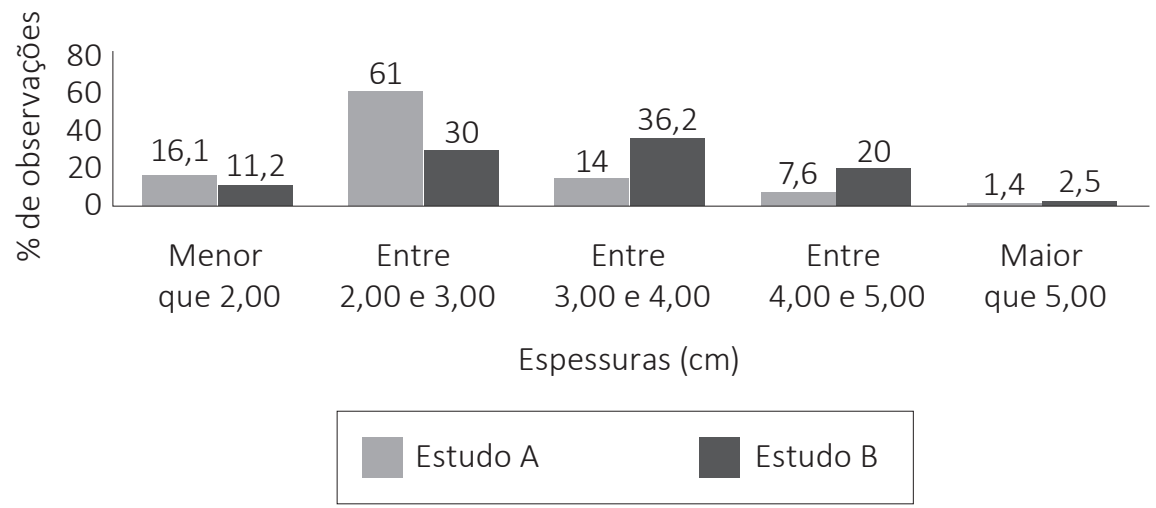

Figura 6 - Distribuição das espessuras do revestimento nos Estudos A e B. 


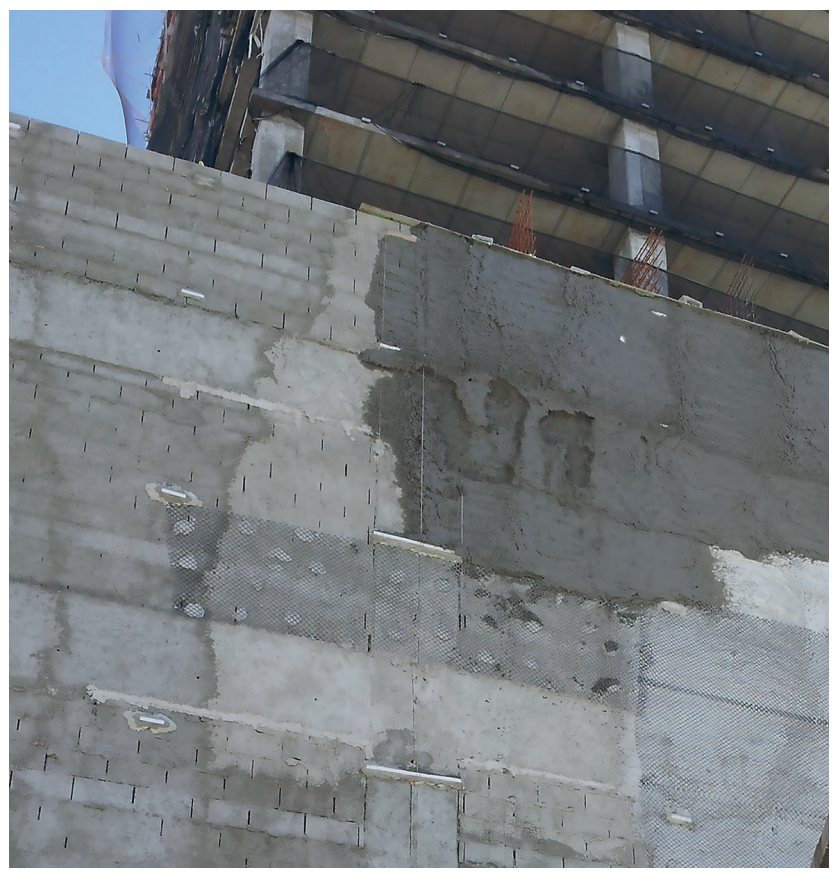

Figura 7 - Descolamento. Fonte: Autores.

Apenas no Estudo D foi identificada o Percentual do Tempo total destinado em Atividades de Transporte (PTAP). As informações obtidas a partir das observações aleatórias indicaram que $34 \%$ do tempo total do processo de revestimento com argamassa ensacada e projeção móvel é destinado a atividades de transporte. Tais Tempos destinados a Atividades de transporte são divididos em: transportes necessários (16\%), como a movimentação dos sacos no elevador cremalheira; transportes evitáveis (15\%), como a movimentação dos sacos entre um estoque secundário e um estoque terciário no andar; e transportes desnecessários (3\%), como a movimentação de um pallet com sacos até um local não preparado para o estoque final da argamassa, conforme apresentado na Figura 8. Neste estudo, ainda foram identificadas algumas das principais causas das perdas por transporte (PÉREZ; COSTA, GONÇALVES, 2016) no processo estudado (Figura 9). 


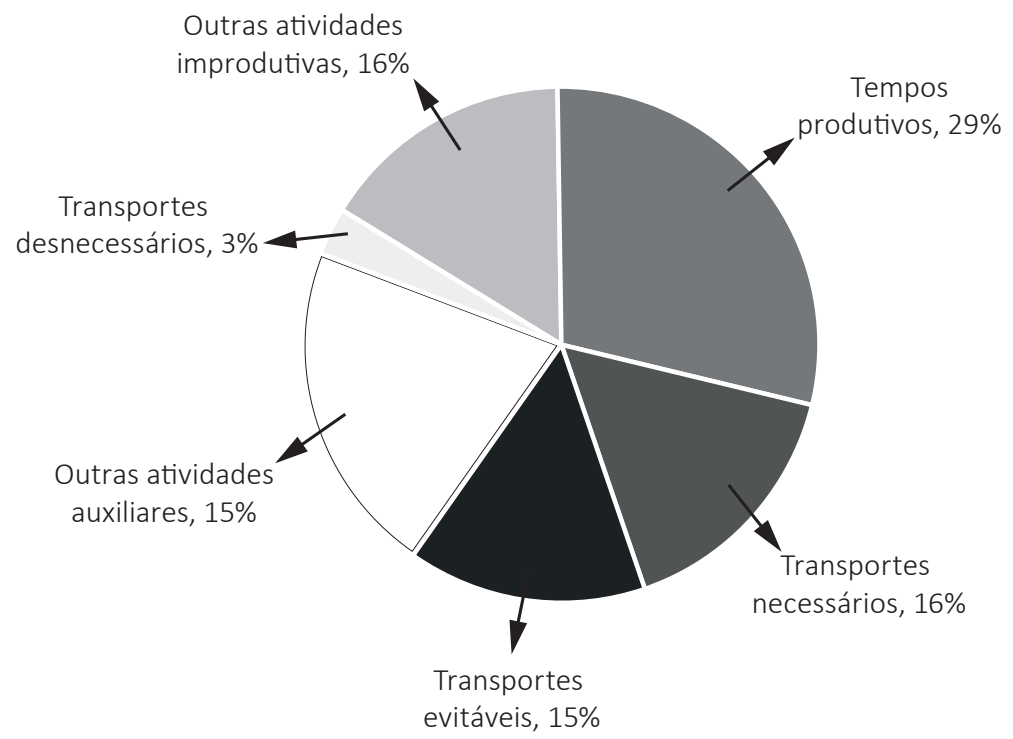

Figura 8 - Resultados da Amostragem de Trabalho no Estudo D. Fonte: Pérez, Costa e Gonçalves, 2015.

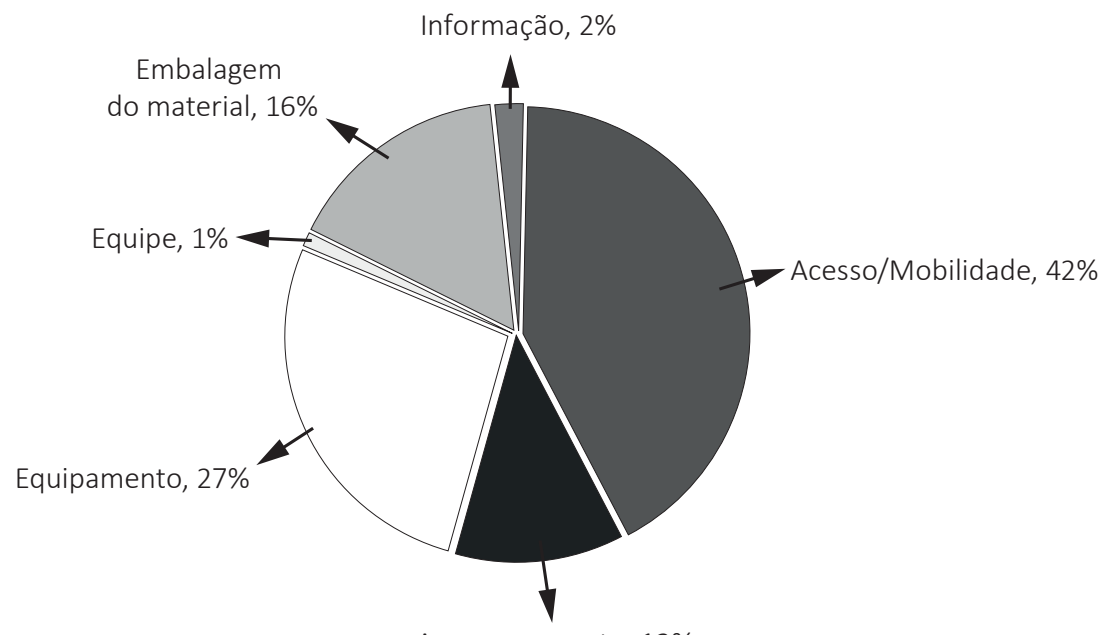

Armanezamento, 12\%

Figura 9 - Causa das perdas nas atividades de transporte. Fonte: Pérez, Costa e Gonçalves, 2015.

A seguir, são apresentados, nas Figura 10, Figura 11 eFigura 12, alguns exemplos das principais causas das perdas por transporte no Estudo D. 


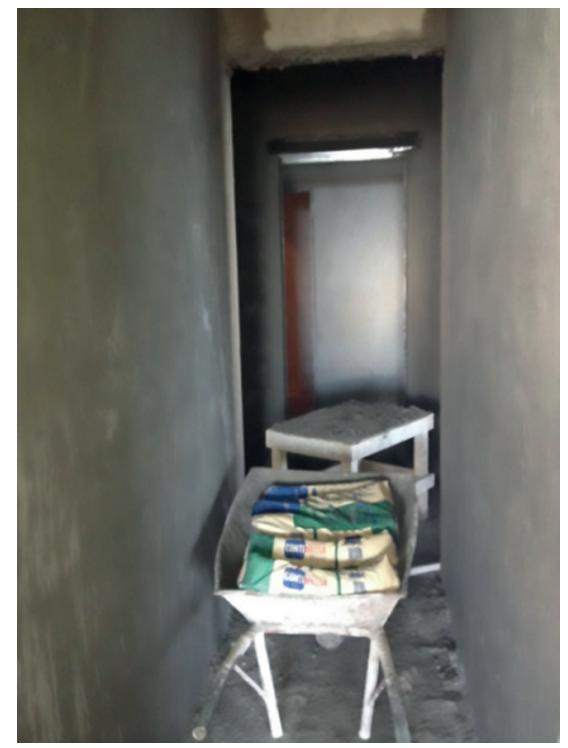

Figura 10 - Perda por acesso (um banco situado na via de acesso dificulta o transporte da argamassa com o carrinho de mão). Fonte: Autores.

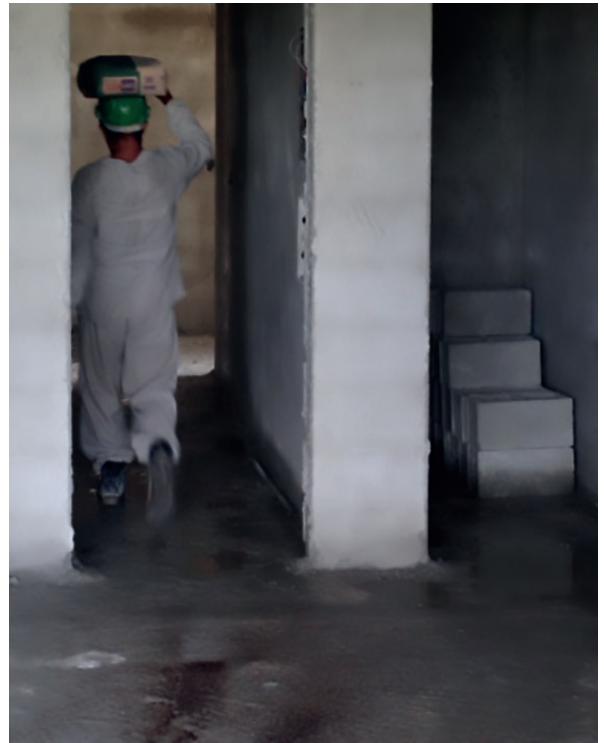

Figura 11 - Perda por equipamento (funcionário transportando sacos manualmente devido à falta de carrinho de mão). Fonte: Autores.

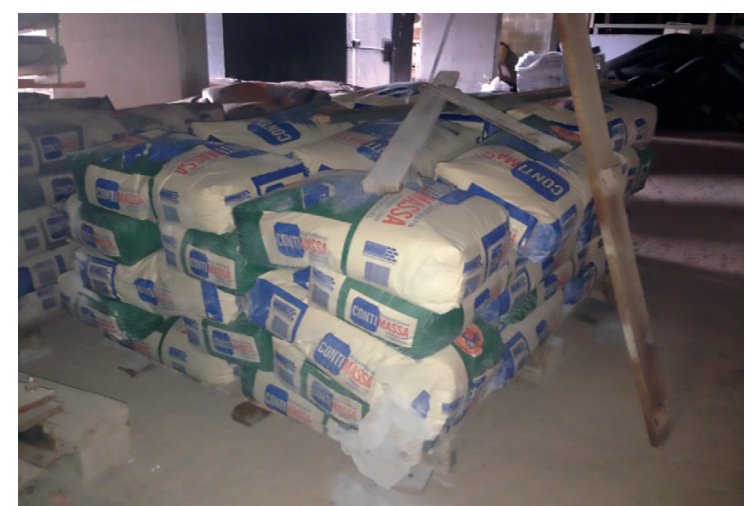

Figura 12 - Perda por embalagem do material (sacos rasgados). Fonte: Autores.

O cálculo dos indicadores econômicos nos estudos indicou que as produtividades do sistema estacionário por via úmida e do sistema de projeção móvel são muito semelhantes, sendo de extrema importância, em ambos os sistemas, um adequado dimensionamento da equipe. No entanto, o sistema de projeção móvel, por ser menos industrializado, destina mais tempo que o sistema de projeção móvel em atividades auxiliares, principalmente em atividades de transporte. 


\subsection{Avaliação Ambiental}

\subsubsection{Nível de Pressão Sonora (NPS)}

O Quadro 7 apresenta os Níveis de Pressão Sonora (NPS) nos locais da realização das medidas, quais sejam: junto aos misturadores e no local da projeção, nos canteiros dos Estudos A, B e C.

Quadro 7 - Nível de Pressão Sonora nos Estudo A, B e C.

\begin{tabular}{|l|l|l|l|}
\hline & Estudo A & Estudo B & Estudo C \\
\hline Tipo de sistema & $\begin{array}{l}\text { Projeção estacionária } \\
\text { por via úmida }\end{array}$ & $\begin{array}{l}\text { Projeção estacionária } \\
\text { por via úmida }\end{array}$ & Projeção móvel \\
\hline $\mathrm{L}_{\text {máximo }}(\mathrm{dBA})$ & 95,0 & 90,3 & 72,5 \\
\hline $\mathrm{L}_{\text {mínimo }}$ (dBA) & 61,3 & 76,9 & 60,0 \\
\hline $\begin{array}{l}\text { Identificação dos } \\
\mathrm{L}_{\text {máx }} \text { e } \mathrm{L}_{\text {mín no }} \text { empreendimento }\end{array}$ & & & \\
\hline
\end{tabular}

Conforme se observa no Quadro 7, os NPS obtidos nos estudos A (95dBA) e B $(90,3 \mathrm{dbA})$ ultrapassam o limite de tolerância de 85 dBA, para a exposição máxima de 8 horas, durante jornada de trabalho, conforme os limites da NR-15 - Atividades e operações insalubres (BRASIL, 2014). Esses valores permitem afirmar que o nível de ruído gerado pelos equipamentos do sistema de projeção estacionaria por via úmida são superiores aos níveis de ruído do sistema de projeção móvel, possivelmente devido à menor potência necessária do misturador móvel para a projeção em decorrência da energia disponível.

\subsubsection{Consumo de água}

No Estudo $A$, foi calculado o consumo de água $(A)$ necessário para a realização do revestimento de dez andares (Figura 13), tendo uma representatividade de 50\%, na medida em que o empreendimento estudado tinha 20 andares. Os valores encontrados mostram que o consumo total de água para a realização de $209,62 \mathrm{~m}^{3}$ de argamassa 
foi de $104,5 \mathrm{~m}^{3}$, obtendo-se, portanto, um valor de $0,5 \mathrm{~m}^{3} / \mathrm{m}^{3}$ para o indicador de Água total consumida na projeção. Cabe ressaltar que menos da metade da Água consumida é gasta no Traço Atraço $\left(54,53 \mathrm{~m}^{3}\right)$.

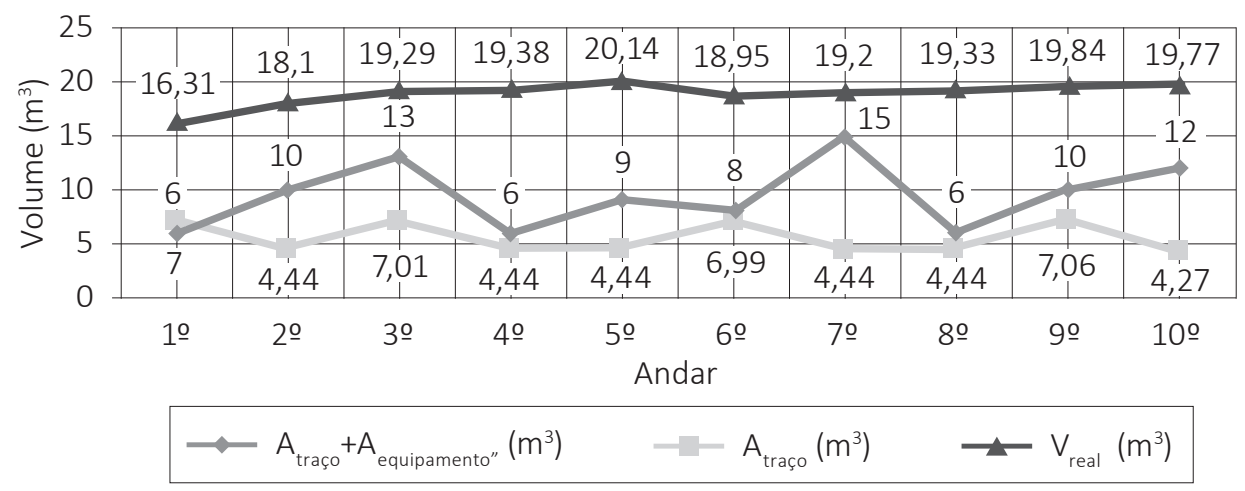

Figura 13 - Consumo de Água total, consumo de Água no Traço e Volume Total de argamassa produzida.

Na Figura 13, observa-se a grande diferença entre o consumo de água total e o consumo de água incorporado na mistura (Atraço), obtida por meio das leituras dos hidrômetro acoplado à boca do reservatório de água (Figura 14). Tal discrepância é decorrente de um consumo excessivo de água na limpeza dos equipamentos (Figura 15).

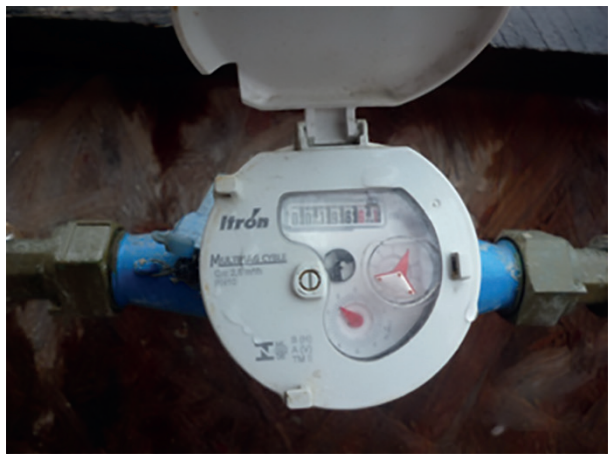

Figura 14 - Hidrômetro acoplado à boca do reservatório de água para a mistura. Fonte: Autores.

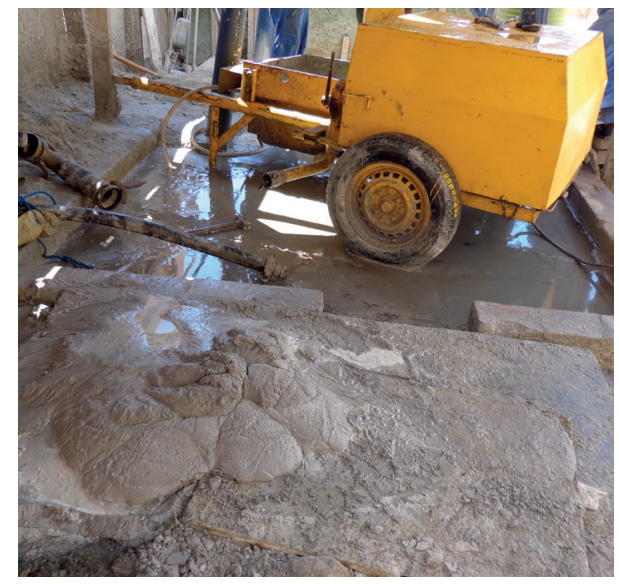

Figura 15 - Limpeza dos equipamentos de mistura. Fonte: Autores. 


\subsubsection{Consumo de energia}

No Estudo A, foi calculado o Consumo de energia elétrica do sistema de projeção (E) durante os meses de estudo, conforme apresentado no Quadro 8. Observa-se que a energia consumida para a projeção de um metro cúbico de argamassa foi em média $1,99 \mathrm{Kwh} / \mathrm{m}^{3}$. O gasto total de energia para a projeção representa $9 \%$ da energia total consumida no mês.

Quadro 8-Energia consumida no Estudo A.

\begin{tabular}{|l|l|l|l|l|l|l|}
\hline & $\begin{array}{l}\text { Energia } \\
\text { consumida no } \\
\text { mês (Kwh) }\end{array}$ & $\begin{array}{l}\text { Dias de } \\
\text { projeção }\end{array}$ & $\begin{array}{l}\text { Energia } \\
\text { consumida } \\
\text { na projeção } \\
\text { (Kwh) }\end{array}$ & $\begin{array}{l}\text { Volume de } \\
\text { argamassa } \\
\text { produzida } \\
\text { (Vreal) }\left(\mathrm{m}^{3}\right)\end{array}$ & $\begin{array}{l}\text { Energia } \\
\left(\text { Kwh/m }{ }^{3}\right)\end{array}$ & $\begin{array}{l}\text { \% de } \\
\text { energia } \\
\text { gasta na } \\
\text { projeção }\end{array}$ \\
\hline Setembro & 2496,78 & 19 & 223,44 & 105 & 2,13 & 9 \\
\hline Outubro & 3231,78 & 22 & 258,72 & 145 & 1,78 & 8 \\
\hline Novembro & 2622,78 & 22 & 258,72 & 140 & 1,85 & 10 \\
\hline Dezembro & 746,45 & 5 & 58,80 & 26 & 2,26 & 8 \\
\hline
\end{tabular}

Por fim, o levantamento dos indicadores ambientais nos estudos indicou que o sistema estacionário por via úmida apresenta maiores impactos que o sistema de projeção móvel, do ponto de vista do NPS, consumo de água e energia.

Dessa maneira, a opção de utilizar projetores de ar para a realização do revestimento, além de contribuir com a qualidade dessa atividade (PARAVISI, 2008), pode ser uma forma de aumentar a produtividade, diminuir as perdas por espessura e aumentar o tempo destinado a atividades produtivas, entre outras. Porém, esse sistema apresenta maiores impactos ambientais diretos, tendo em vista o NPS, o consumo de água gasto para a limpeza dos equipamentos e a energia utilizada pelos equipamentos de projeção (Figura 16). No entanto, a partir de uma ponderação mais ampla, considerando os impactos indiretos, a redução do prazo das atividades reduzirá também atividades inerentes ao funcionamento da obra como um todo. Deste modo, uma análise mais aprofundada e individualizada é de grande importância, já que tal ganho de produtividade pode acarretar na compensação dos impactos ambientais diretos. 


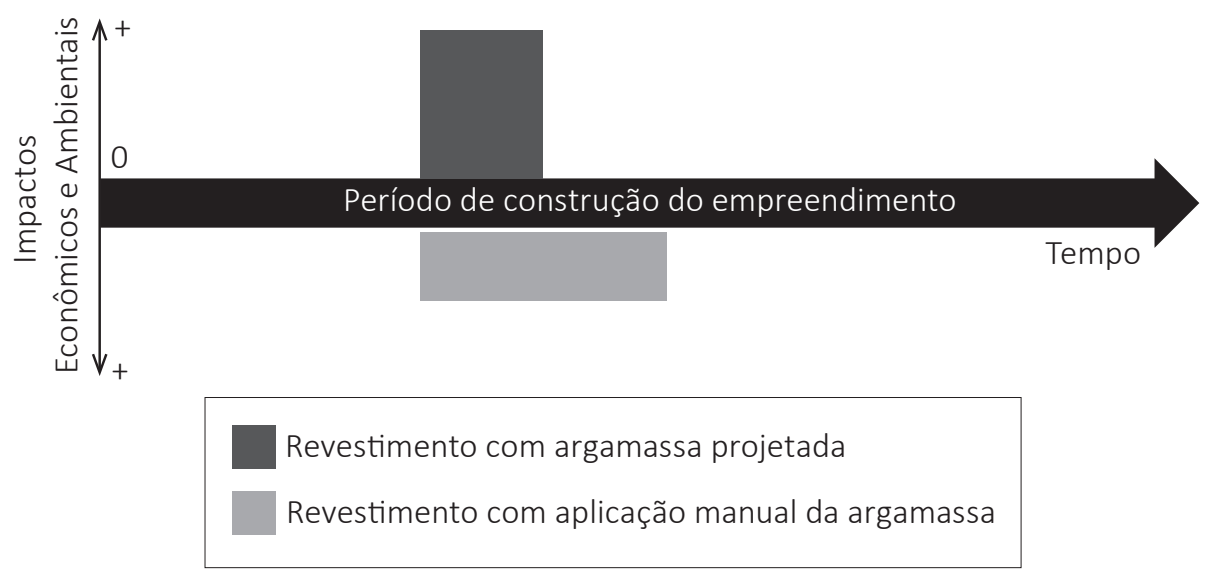

Figura 16 - Comparação dos impactos econômicos e ambientais ao longo do período de construção de um empreendimento.

\section{Conclusões}

O presente capítulo apresentou uma análise econômica e ambiental do processo de revestimento com argamassa projetada a partir dos indicadores coletados em quatro estudos de caso realizados na região metropolitana de Salvador.

Entre os indicadores econômicos utilizados o PTP e o PTAT foram aqueles que exigiram um maior esforço na sua coleta, devido à necessidade do uso da técnica da amostragem de trabalho, consumindo bastante tempo de pesquisa. Por outro lado, esses indicadores permitiram realizar uma quantificação dos tempos destinados em atividades produtivas e de transporte no processo estudado. Já o indicador RUPc mostrou-se como um indicador de coleta bastante simples, feita a partir da planilha de controle da produção. Os resultados obtidos a partir da coleta da RUPc foram importantes para a quantificação da produtividade dos sistemas de projeção. Por último, embora o indicador Pvar. ${ }_{\text {esp. }}$ demande uma coleta de amostras das espessuras das superfícies a revestir, nem sempre de fácil acesso, sua análise é importante porque a variação de espessura é apontada como uma das principais fontes de perdas de argamassa no processo de revestimento com argamassa.

Já entre os indicadores utilizados para a avaliação ambiental, o indicador NPS é de simples coleta, demandando apenas o uso de um decibelímetro. Para o cálculo do Consumo de água na projeção (A), observa-se a necessidade da existência de um hidrômetro no reservatório para a realização efetiva do controle de água utilizado. Tal equipamento apresenta um custo baixo em relação ao benefício econômico que o 
referido controle pode trazer. Por fim, a coleta do Indicador Consumo de Energia (E) mostrou-se simples, tendo sido realizada a partir das informações dos equipamentos oferecidos pelo fabricante e de outras informações obtidas com as planilhas de controle de argamassa, também de fácil aplicação.

Do ponto de vista da avaliação dos sistemas de argamassa projetada estudados nesta pesquisa, a coleta de indicadores de produtividade indicou que os sistemas de projeção estacionários por via úmida apresentam ganhos de produtividade em relação ao sistema de projeção móvel. De acordo com resultados obtidos, o sistema de projeção estacionário por via úmida utilizado nas obras A e B apresenta o NPS mais elevado (95 dBA) que o sistema de projeção móvel ( $72,5 \mathrm{dBA})$. Conclui-se que os operadores das argamassadeiras analisadas estão submetidos a níveis de ruídos aceitáveis. Ainda assim, ações de mitigação dos ruídos são recomendadas. Os resultados obtidos na coleta do Indicador Energia consumida para a projeção (E) indicaram que são gastos em media 1,99Kwh para a projeção de um metro cúbico de argamassa. O gasto total de energia para a projeção representa $9 \%$ da energia total consumida no mês no canteiro da Obra A.

\section{Referências}

ABNT. Associação Brasileira de Normas Técnicas. Revestimento de paredes e tetos de argamassas inorgânicas - Especificação. NBR 13749: Rio de Janeiro, 1996.

BRASIL. Ministério do Trabalho e Emprego. Norma Regulamentadora 15 (NR-15): Atividades e Operações Insalubres. 2014. Disponível em: <http://portal.mte.gov.br/data/ files/8A7C816A47594D040147D14EAE840951/NR-15\%20(atualizada\%202014).pdf>. Acesso em: nov. 2014.

COSTA, F.N. Processo de produção de revestimento de fachada de argamassa: problemas e oportunidades de melhoria. 2005. Dissertação (Mestrado em Engenharia Civil) - Programa de Pós-graduação em Engenharia Civil, UFRGS, Porto Alegre.

CRESCENCIO, R.M.; PARSEKIAN, G.A.; BARROS, M.M.S.B.; SABBATINI,F.H. Execução de revestimento com argamassa projetada. São Paulo, 2000. EPUSP.

IIDA, I. Ergonomia: projeto e produção. 2. ed. rev. e ampl. São Paulo: Edgard Blücher, 2005. OLVIVEIRA, M.; LANTELME, E.; FORMOSO, C. T. Sistemas de indicadores de qualidade e produtividade para a construção civil: manual de utilização. 2. ed. rev. Porto Alegre: Serviço e Apoio às Micro e Pequenas Empresas do Rio Grande do Sul - SEBRAE/RS, 1995.

PALIARI, J.C.; SOUZA, U.E.L.; ANDRADE, A.C. Levantamento de perdas/consumo de argamassas de revestimento em obras de construção de edifícios brasileiras. In: III Simpósio Brasileiro de Tecnologia de Argamassas, Vitória, 1999. Anais... Vitória, 1999, p. 175-724.

PALIARI, J.C.; SOUZA, U.E.L.; ANDRADE, A.C. Estudo sobre consumo de argamassa de revestimentos interno e externo nos canteiros de obras. In: Simpósio Brasileiro de Gestão da Qualidade e Organização do Trabalho no ambiente Construído, 2o, Fortaleza, CE, 2001. 
PARAVISI, S. Avaliação de sistemas de produção de revestimentos de fachada com aplicação mecânica e manual de argamassa. Dissertação (Mestrado em Engenharia Civil) Núcleo Orientado Para Inovação da Edificação, Programa de Pós-Graduação em engenharia civil, Universidade Federal do Rio Grande do sul, Porto Alegre, 2008.

PARAVISI, S.; MASUERO, A.B.; BONIN, L.C.; ISATTO, E.L. Produção de argamassa com bomba de projeção. Revista Téchne. PINI. Edição 145. Abril, 2008.

PÉREZ, C.T.; COSTA, D.B.; GONÇALVES, J.P. Identificação, mensuração e caracterização das perdas por transporte em processos construtivos. Ambiente Construído, Porto Alegre, v. 16, n. 1, p. 243-263, jan./mar. 2016. ISSN 1678-8621, Associação Nacional de Tecnologia do Ambiente Construído. http://dx.doi.org/10.1590/s1678-86212016000100072

RODRIGUES, P.P.; CATAI, R.E.; AGNOLETTO, R.A.; FERREIRA, M.R.C.; GUDEIKI, I.J.B.; MATOSKI, $A$. Análise dos níveis de ruído em equipamentos da construção civil na cidade de Curitiba. 2009. Revista Produção. ISSN 1676 - 1901 / v. IX, n. III, 2009.

SANTOS, A.; FORMOSO, C.T.; HINKS, J. Method of Intervention on the Flow of Materials in Buildings Processes. In: ANNUAL CONFEENCE OF THE INTERNATIONAL GROUP FOR LEAN CONSTRUCTION, 4., Birmingham, 1996. Proceedings... Birmingham, 1996.

SILVA R.R.; VIOLIN, R.Y.T. Gestão da água em canteiros de obras de construção civil. VIII EPCC Encontro Nacional de Produção cinetífica, 2013. Anais... 2013

SOUZA, R.; MEKBEKIAN, G. Qualidade na aquisição de materiais e execução de obras. CTE. São Paulo, PINI, 1996. 